\title{
REVITALISASI IDE BANGSA DALAM CERPEN KǑNG YǏJII (孔乙己) (1919) KARYA LU XUN
}

\author{
Padel Muhamad Rallie Rivaldy \\ Komunitas Sastra RUSABESI \\ rallierivaldy@gmail.com
}

\begin{abstract}
Abstrak
Karya sastra Cina pada masa Gerakan Kebudayaan Baru tidak dapat dipisahkan dari realitas masyarakatnya. Oleh karena itu, diperlukan pengetahuan sejarah dan sosio-politik untuk memahami sastra Cina secara mendalam. Salah satu penulis yang merekam masa transisi dari pemerintahan Dinasti Qing ke Republik dan dianggap sebagai penggagas sastra Cina modern adalah Lu Xun. Dengan pendekatan sosiologi sastra, tulisan ini bertujuan untuk menunjukkan revitalisasi gagasan berbangsa yang terdapat dalam cerpen “Kǒng Yrijǐ” (孔乙己) (1919) karya Lu Xun. Tulisan ini akan melibatkan unsur ekstrinsik, yaitu konteks sosial ketika karya tersebut diproduksi. Namun, tulisan ini juga tetap akan menjelaskan analisis pembacaan dekat (close reading) cerpen tersebut untuk memperdalam analisis. Hasil temuan menunjukkan adanya komitmen pengarang untuk menghidupkan kembali ide bangsa yang lepas dari nilai-nilai lama melaui cerpennya. Pudarnya nilai-nilai lama tersebut direpresentasikan secara simbolis melalui tokoh Kong yang hidup di tengah masyarakat Cina.
\end{abstract}

Kata kunci: Lu Xun; bangsa; revitalisasi

\begin{abstract}
Chinese literary works in the time of New Cultural Movement are interrelated with the reality of Chinese society at that time. Therefore, the knowledge upon historical aspect and socio-political circumstances are needed to gain deep understanding of a single literary work. One of distinguished author which represent the transition of Qing Dynasty to Republic Era of China and is regarded as the pioneer of modern Chinese literature is Lu Xun. By elaborating sociological approach, this article aims to observe the revitalization of nation's idea in “Kǒng Yíju”" (孔乙己) (1919) short story by Lu Xun. This article elaborates extrinsic elements that cover social context on which the work is produced. However, close reading analysis is also applied in order to preserve in-depth analysis. This article finds out that the author, through his work, builds a commitment to revitalize the idea of nation which step over traditional values. The degradation of those traditional values symbolically represented through Kong's life among Chinese society.
\end{abstract}

Keywords: Lu Xun; nation; revitalization

\section{Pendahuluan}

Dalam bingkai sosiologi sastra, karya sastra tidaklah lahir semata-mata dari kekosongan, melainkan lahir dari dinamika masyarakat dan dapat menjadi rekaman atas kejadian di sekitarnya. Oleh karena itu, karya sastra memiliki potensi untuk menggam- barkan sebuah kondisi zaman tertentu (Watt dalam Damono, 1978). Dengan berpaku pada paradigma ini, kajian ini membahas sosok Lu Xun sebagai salah satu sosok sastrawan penting yang merekam periode transisi dari masa Dinasti kepemerintahan Republik dalam 
Poetika : Jurnal Ilmu Sastra

Vol. VII No. 1, Juli 2019

konteks negara Cina. Salah satu cerpennya, “Kǒng Y̌̌jǐ” (孔乙己) (1919), menceritakan kisah seorang intelektual pemabuk yang terasing di tengah lingkungan sosialnya.

Lu Xun lahir tepat tiga puluh tahun sebelum kejatuhan pemerintahan Dinasti Qing, yaitu pada 1881, di Shaoxing, salah satu provinsi di Zhejiang, bagian timur Cina. Nama yang ia sandang sejak lahir adalah Zhou Zhangshou. Akan tetapi pada tahun 1898, ketika ia memasuki Nanjing Naval Academy, ia melepas marga ayah dan mengubah namanya menjadi Zhou Shuren. Pada masa ini, Lu Xun mulai belajar tentang sains medis, pemikiran evolusioner, dan melirik perkembangan Jepang, yang sudah terbuka terhadap pengetahuan Barat semenjak 1868 (era Meiji). Oleh karena itu, setelah lulus dari akademi pada 1902, ia mengambil kesempatan untuk mempelajari lebih dalam ilmu medis di Universitas Sendai, Honshu, Jepang. Namun, di tengah masa pelatihannya, Lu Xun memutuskan untuk berhenti dari studi setelah menyaksikan kekejaman Zou Rong (18851905) dan eksekusi orang-orang Cina selama perang Russo-Japanese, ketika Jepang mengambilalih Manchuria, dalam sebuah film newsreel (Hsia, 1961:30, Tambling, 2007:13-15).

Semenjak masa itu, Lu Xun mulai menumbuhkan semangat untuk membangun bangsa Cina, yang ia sebut sedang sakit secara mental, melalui gerakan sastra, seperti dijelaskan dalam Preface dalam Kumpulan Cerpen A Call to Arms: 10.22146/poetika.44389

ISSN 2338-5383 (print) ; 2503-464 (online)

"Before the term was over, I had left for Tokyo, because this slide convinced me that medical science was not so important after all. The people of a weak and backward country, however strong and healthy they might be, could only serve to be made examples of or as witnesses of such futile spectacles, and it was not necessarily deplorable if many of them died of illness. The most important thing, therefore, was to change their spirit, and since at that time I felt that literature was the best means to this end, I decided to promote a literary movement." (Xun, 1980:35)

Pada tahun 1911, ia menulis cerpen pertama yang ditulis dalam bahasa Cina klasik berjudul Huai Jiu dan diterbitkan dalam The Short Story Magazine pada 1913 dengan nama pena yang pernah dipakai saudaranya-Zhou Chuo (Tambling, 2007:18). Setelahnya, ia mulai menjadi kontributor majalah New Youth (新青年) dengan menerbitkan cerpen. Pada masa ini, ia pertama kali menggunakan LuXun sebagai nama pena, yang berarti bodoh (鲁) dan cepat atau tiba-tiba (迅). Cerpen kedua Lu Xun yang terbit di majalah tersebut berjudul "Kǒng Yǐjī”.

Foley dalam Between Human and Animal (2012) menjelaskan dehumanisasi tokoh dalam tiga cerpen Lu Xun; "New Year's Sacrifice", "Kǒng Y̌ijǔ”, dan "Diary of a Madman”, sebagai bentuk teka-teki metafisis dengan mengelaborasi pandangan Giorgio Agamben. Analisisnya menunjukkan dehumanisasi para tokoh dalam ketiga cerpen menempatkan mereka dalam ambang, yang belum dan tidak mungkin, 'menjadi' melalui penggambaran kematian atau kepulihan mereka di tengah masyarakat Cina. Analisis Foley membantu memahami gagasan yang dihadirkan oleh cerpen Lu Xun dengan perspektif yang kaya meskipun ia mengesamping- 
kan agenda dari Fourth May Movement. Namun, tulisan ini berargumen bahwa selain analisis intrinsik, aspek ekstrinsik dari karya Lu Xun tidak dapat dipisahkan dalam rangka memperoleh pemaknaan yang lebih mendalam.

Wuryandari dalam Kesusastraan Kontemporer Cina (2006:172-173) mencatat karya sastra dan kebijakan pemerintah atau kondisi sosial-politik, ketika karya tersebut diproduksi, saling berhubungan satu sama lain. Contohnya, pada sastra masa republik, setelah jatuhnya pemerintahan Dinasti Qing pada 1911, terjadi perubahan tren sastra. Pada masa itu, banyak kaum intelektual yang berupaya meninggalkan nilai-nilai lama yang masih berpegang teguh pada feodalisme dan konfusianisme. Selain itu, gaya kesusastraan Barat banyak diadopsi oleh para pengarang asal Cina, dan banyak karya Barat terjemahan yang diperkenalkan kepada masyarakat Cina.

Tulisan ini bertujuan untuk menjelaskan bagaimana cerpen "Kǒng Y̌̌jǐ" (孔乙己) (1919) karya Lu Xun menghidupkan ide tentang bangsa Cina yang lepas dari nilai-nilai feodalisme dan konfusianisme. Dalam analisis, kajian ini menggunakan metode pembacaan dekat (close reading) oleh Brummet (2009), yang berarti tidak hanya terpaku pada bagian besar dari sebuah narasi, tetapi juga menaruh perhatian pada bagian-bagian yang menyusun sebuah teks, seperti penggunaan bahasa, sudut pandang, simbol, personifikasi, alusi, dan lain sebagainya.
Selain itu, pendekatan sosiologi sastra juga digunakan sebagai alat bantu analisis, sehingga selain analisis tekstual, penulis juga akan mengelaborasi unsur ekstrinsik, yaitu konteks sosial ketika karya tersebut diproduksi. Sebagaimana dijelaskan oleh Watt (dalam Damono, 1978), dalam bingkai sosiologi sastra, sebuah karya sastra dapat dipertimbangkan sebagai satu produk yang mampu merepresentasikan persoalan sosiologi, yaitu tentang masyarakat dan segala aktivitas di sekitar mereka (1979:68). Sementara itu, data yang digunakan dalam tulisan ini adalah cerpen "Kǒng Y̌̌jī” versi bahasa Inggris, yang diterjemahkan oleh Yang Xianyi dan Gladys Yang.

\section{Pembacaan Dekat (Close Reading) atas Cerpen "Kǒng Yǐjǐ”}

Cerita pendek "Kǒng Yřjǐ" pertama kali diterbitkan pada Maret 1919 sebelum kemudian dimasukkan dalam kumpulan cerpen A Call to Arms (呐喊). Sementara itu, majalah New Youth atau Xin Qingnian sendiri mulai diterbitkan pada 1915 oleh Dekan College of Literature Universitas Peking sekaligus salah satu tokoh yang nantinya menjadi pendiri partai Komunis, Chen Dixiu. Selama masa produksinya, majalah tersebut dikelola oleh ikatan pengajar di Universitas Peking, yang berdiri pada 1898, dan menjadi batu tonggak munculnya 'New Culture Movement' (Tambling, 2007:18-19). Melalui karya-karyanya, Lu Xun dikenal sebagai pencetus sastra modern di Cina dengan mengelaborasi gaya penceritaan yang digunakan dalam 
sastra Barat (Hsia, 1961:28, Guo, 2006:18). Selain itu, diketahui pula gaya estetik yang ia pakai juga banyak terpengaruh oleh sastrawan Rusia, khususnya Gogol (Fokkema, 1977:90).

Secara struktur, cerpen "Kǒng Y̌̌jǐ" diceritakan melalui sudut pandang seorang anak berusia dua belas tahun yang bekerja di sebuah kedai anggur di daerah Luzhen. Melalui sudut pandang orang pertama tersebut, diceritakan kisah seorang intelektual bermarga Kong. Walaupun memiliki kemahiran berbahasa dan menulis, Kong tidak pernah lulus dalam ujian pegawai negeri, sehingga mengalami kesulitan untuk bertahan hidup. Ia tidak berusaha melakukan pekerjaan lain, kecuali menjadi seorang penyalin dokumen dan kaligrafer bagi orang-orang kelas atas. Di satu sisi, Kong adalah sosok yang penuh dengan ketidakberdayaan dengan segala pendirian, yang ia pegang teguh. Di sisi lain, keteguhan pendiriannya tersebut yang membuatnya tidak merasa bersalah ketika tertangkap melakukan pencurian buku, dan hanya menjawab:

"Taking a book can't be considered stealing, ... Taking a book, the affair of a scholar, can't be considered stealing!" (Xun, 1980: 53).

Penokohan Kong dalam cerpen "Kǒng Y̌̌jǐ” dibangun sebagai kontras, dalam arti digambarkan berbeda dengan lingkungan sekitarnya. Perbedaan ini dapat diklasifikasikan dalam beberapa kriteria, antara lain: gaya bahasa, fesyen dan penampilan fisik, serta kepercayaan yang Kong pegang. Melalui perbedaan ini, dapat dilihat bagaimana Kong memosisikan diri dan diposisikan di tengah masyarakat Cina, yang digambarkan dalam cerpen. Selain itu, konteks sosial sebagai unsur ekstrinsik, yang telah dijelaskan pada bagian sebelumnya, dapat membantu menafsirkan simbol-simbol yang tersirat dalam cerpen.

Pertama, komunikasi antara Kong dengan orang-orang di sekitarnya terhambat, karena bahasa yang digunakannya tidak mudah dipahami. Akibatnya, ia secara tidak langsung merasakan keterasingan di tengah lingkungannya, seperti dijelaskan dalam kutipan di bawah:

"He used so many archaisms in his speech that half of it was barely intelligible. And as his surname was Kong, he was given nickname Kung Yiji from kong, yi, ji, the first three characters in the old-fashioned children's copybook. Whenever he came in, everyone there would look at him and chuckle. And someone was sure to call out: Kung Yiji! What are those fresh scars on your face!" (Xun, 1980:53)

Dari kutipan di atas dapat diketahui meskipun Kong adalah seorang intelektual yang memiliki kemahiran berbahasa, orang-orang di sekitarnya tidak dapat memahami apa yang dimaksud dari ungkapan-ungkapan arkaisnya. Oleh karena itu, Kong tidak pernah dianggap berwibawa di hadapan orang-orang di sekitarnya. Ia juga tidak jarang menjadi bahan tertawaan oleh anak-anak, yang menjulukinya 'Kǒng Y̌̌jǐ'. Terlebih lagi, ia hanya dianggap sebagai penghibur dalam kesuraman di kedai anggur oleh narator.

Kedua, gaya berpakaian dan ciri fisik Kong berbeda dengan orang-orang di sekelilingnya. Secara tidak langsung gaya berpakaian tersebut 
menunjukkan bahwa ia adalah seorang yang berbudaya, meskipun keadaannya memprihatinkan, seperti dijelaskan pada kutipan:

"'Kǒng Yìjĭ" was the only long-gowned costumer who used to drink his wine standing. A big, pallid man whose wrinkled face often bore scars, he had a large, unkept and grizzled beard. And although he wore a long gown, it was dirty and tattered. It had not by the look of it been washed or mended for ten years or more." (Xun, 1980:53)

Kutipan di atas menunjukkan bahwa pakaian jubah yang dipakai Kong sudah usang, sehingga kesan yang didapatkannya bukanlah kharisma, melainkan tertawaan dari orang-orang. Penampakan usang dari jubah Kong yang dijelaskan di atas dapat menjadi gambaran simbolis bahwa kedudukan kaum feodal sudah tidak lagi diagungkan dan malah menjadi bahan olok-olok di tengah masyarakat.

Ketiga, kepercayaan yang dipegang teguh Kong tersirat dari ungkapan-ungkapan arkais yang ia sampaikan. Walaupun ungkapannya mengandung makna yang mendalam, orang di sekeliling Kong tidak dapat memahami apa yang ia maksud, seperti dijelaskan pada kutipan:

"At that Korng Yijiı would flush, the veins on his forehead standing out as he protested [...] Then followed such quotation from the classics as " $A$ gentleman keeps his integrity even in poverty," together with a spate of archaism which soon had everybody roaring with laughter, enlivening the whole tavern." (Xun, 1980:53-54)

Ungkapan yang tedapat dalam kutipan di atas, yaitu: "A gentleman keeps his integrity even in poverty" menjadi alusi pada kutipan yang terdapat dalam Analect of Confucious.
Ungkapan tersebut bermakna karakter sejati seorang laki-laki sejati tidak dimaknai berdasarkan apa yang diperbuatnya di depan khalayak ramai, tetapi apa yang dia lakukan ketika tidak ada satu orang pun yang melihatnya. Kutipan di atas menyiratkan perbedaan Kong dengan orang-orang di sekitarnya juga terletak pada hal yang paling subtil dan mendasar, yaitu kepercayaan konfusianisme. Akan tetapi, pekerjaannya sebagai "occasional pilfering" justru menampilkan kontradiksi, sehingga ungkapannya malah menjadi bahan tertawaan.

Berdasarkan penjelasan di atas, penulis menemukan sosok Kǒng Yǐjǐ adalah cerminan dari masyarakat Cina yang masih memegang teguh nilai-nilai lama. Kǒng Y̌̌jǐ adalah representasi dari kaum intelektual Cina yang kehidupannya digambarkan dalam ruang publik, sebagai penjaga wibawa, dan dalam ruang privat, sebagai pencuri dari kelas atas. Dia memiliki kebutuhan untuk mempertahankan kewibawaan sebagai seorang berpendidikan dan kelas atas di hadapan publik orang Cina kebanyakan, melalui gaya bahasa, pakaian, dan nilai-nilai yang ia pegang teguh. Akan tetapi, terdapat paradoks dalam perilakunya, yang malas dan menganggap mencuri buku bukan sebagai bentuk kejahatan, sehingga ia tidak merasa bersalah atas perbuatannya.

\section{“Kǒng Yǐjǐ” dan Gerakan Kebudayaan Baru}

Sebagaimana dijelaskan Watt (dalam Damono, 1978), terdapat dua kecenderungan metode yang dipakai dalam sosiologi sastra. 
Pertama, pendekatan yang mendasar pada anggapan bahwa karya sastra sebagai cermin dimensi sosial dan ekonomi, yang mengedepankan faktor-faktor di luar karya sastra ketika melakukan analisis pada sebuah karya sastra. Namun, kajian ini lebih mempertimbangkan kecenderungan kedua, yaitu metode pendekatan yang mengutamakan teks sastra sebagai bahan telaah. Dengan menggunakan metode pendekatan ini, karya sastra kemudian dapat menjadi bahan untuk memahami gejala sosial yang menjadi konteks ketika karya tersebut diproduksi. Oleh karena itu, pendekatan ini dapat membantu untuk memahami gejala sosial yang digambarkan dalam sebuah karya sastra dan keadaan nyata yang berada di luar sebuah karya sastra.

Menurut Zhang, cerpen "Kǒng Y̌rjị” menjadi satu contoh nyata bagaimana media dan institusi baru, membentuk jalan yang mengarah kepada sastra Cina modern (2016:368). Terlebih lagi, pada masa tersebut juga muncul upaya dari para pembaharu untuk mengusulkan bentuk kesusastraan baru yang lepas dari feodalisme dan nilai-nilai besar Barat. Khususnya, dalam penggunaan gaya bahasa dalam menulis sastra yang tidak lagi menggunakan wenyan, tetapi menggunakan baihua atau bahasa sehari-hari. Setelah diresmikan sebagai bahasa nasional, penggunaan bahasa, topik, dan penokohan dalam karya sastra Cina mengalami banyak perubahan dibanding karya sastra yang diproduksi pada masa kedinastian
(Wuryandari, 2006: 173).

Apabila dikaitkan dengan aspek kesejarahan dan pandangan Lu Xun sebagai pengarang, cerpen "Kǒng Y̌ijị" menunjukkan secara simbolis personifikasi dari penyakit batin yang menjangkit jati diri bangsa Cina. Marga Kong sendiri merepresentasikan keturunan keluarga paling tinggi dalam strata masyarakat Cina, dan memiliki kaitan dengan ajaran konfusius. Namun, cerpen ini menghadirkan ironi melalui tokoh Kong, sebagai manusia yang tidak berdaya dan tidak mampu melawan, kecuali merangkak dengan kakinya, yang cacat karena dipukuli. Melalui tokoh Kong, cerpen ini menggambarkan secara simbolis kegagalan bangsa Cina untuk melawan semua dorongan dari luar, seperti invasi negeri asing, adalah karena kelemahan yang bersifat batiniah dalam karakter bangsa Cina, yang dipersonifikasikan melalui kekukuhan pendirian dan mental yang sakit pada sosok Kong.

Melalui "Kǒng Y̌̉jǐ”, Lu Xun menunjukkan komitmennya untuk membangun bangsa Cina. Keberadaan Kong di tengah ruang publik, yaitu kedai Luchen, dihadirkan berbeda melalui cara dia minum dan diperlakukan oleh lingkungan sekitarnya. Di tengah masyarakat yang tidak mensyaratkan kelas dalam berinteraksi, Kong tetap mencoba menunjukkan kebangsawanannya, melalui bahasa dan fesyen. Akan tetapi, penggunaan bahasa arkais yang tidak dapat dimengerti, dan atribut yang digunakan, yaitu jubah usang, menyimbolkan bahwa nilainilai lama sudah dianggap kuno dan tidak relevan untuk membangun bangsa dan membim- 
bing Cina ke arah yang lebih baik. Bahkan, Kong dengan kondisi yang demikian tidak memiliki kemampuan untuk membela dirinya sendiri:

"I fell, [...] his eyes pleaded with the boss to let the matter drop." (Xun, 1980:57)

Lebih jauh lagi, ketidakrelevanan nilainilai tradisional ini ditunjukkan melalui diabaikannya posisi marga Kong beserta nilainilai ajaran luhur yang dipegangnya. Hal ini digambarkan secara simbolis melalui pengajaran bahasa yang dilakukan Kong kepada narator. Kutipan di bawah menjelaskan bahwa narator menganggap Kong telah menunjukkan perlakuan yang tidak tahu diri.

"Have you had any schooling?" When I nodded curtly he said, "Well, I'll test you. How do you write the hui in anisheed-peas?" Who did this beggar think he was, testing me! I turned away and ignored him [...] I don't need you to show me. Isn't it the hui written with the element for grass!" (Xun, 1980:55)

Ketidakberdayaan Kong untuk berkomunikasi dengan lingkungannya membimbingnya untuk menjalin hubungan dengan anak-anak. Namun, di lingkungan anak-anak pun ia tetap mendapat penolakan dan menjadi bahan tertawaan, seperti dijelaskan dalam kutipan di atas. Adegan di atas secara tidak langsung menyiratkan adanya ketidakmungkinan pewarisan nilai-nilai lama kepada generasi muda, seperti sosok narator. Selain itu, fakta bahwa Kong tidak dapat lulus dalam "official examination" mengindikasikan seorang individu yang kukuh dengan nilainilai lama tidak dapat lagi masuk ke dalam jabatan birokrasi.
Cerpen "Kǒng Y̌̌jī" secara tidak langsung menyasar para intelektual Cina atas kegagalan dalam merevolusi masyarakat Cina untuk bangkit. Dengan kata lain, kegagalan bangsa Cina untuk melawan imperialisme Barat disebabkan kegagalan para tokoh intelektual untuk meningkatkan kualitas diri bangsa Cina ke tahap yang lebih baik. Apabila dikaitkan dengan pandangan Lu Xun, kegagalan bangsa Cina juga tidak hanya dapat dilihat dari ketidakberhasilan para kaum intelektual, tapi juga dari kalangan masyarakat Cina itu sendiri. Permasalahan masyarakat sipil ini mungkin menjadi batas dari analisis dari cerpen "Kǒng Yrijǐ”, dan lebih tepat untuk dielaborasi dalam cerpen Medicine (药).

Seperti dijelaskan dalam bagian sebelumnya, cerpen "Kǒng Y̌rjǐ” dipublikasikan pertama kali di majalan Xin Qingnian. Majalah tersebut merupakan bagian dari agenda para pembaharu Cina yang tergabung dalam New Cultural Movement (Tambling, 2007:18). Ide yang diusung dalam cerpen ini sejalan dengan gagasan revolusi kebudayaan bangsa Cina. Hal ini diwujudkan melalui medium penulisan bahasa, yaitu baihua, yang dimaksudkan untuk menggantikan bahasa wenyan ala kaum feodal. Walaupun gaya penceritaan dalam cerpen "Kǒng Yrijì" mengadopsi gaya Barat, gagasan yang dibawa dalam cerpen tersebut menjelaskan bahwa pengarang menunjukkan komitmennya untuk membentuk bangsa Cina yang lebih baik.

Cerpen "Kǒng Y̌̌jǐ" memiliki "fungsi sosial" (Watt dalam Damono, 1978:5) melalui 
penggambaran simbolis jatuhnya nilai-nilai lama dan pada saat bersamaan menjadi refleksi bagi para pembacanya. Melalui cerpen ini, pembaca mendapatkan gambaran lunturnya nilai-nilai lama, yang disimbolkan melalui sosok Kong. Nilai-nilai lama yang dimaksud adalah ajaran konfusianisme dan tradisi feodalisme. Melalui cerpen ini, pengarang berupaya untuk menghidupkan kembali gagasan berbangsa di bawah semangat revolusi budaya. Seperti dijelaskan di atas, nilai-nilai lamalah yang membuat bangsa Cina sakit secara mental seumpama Kong, yang tetap menjaga wibawanya walaupun kondisinya memprihatinkan.

Judul dari cerpen ini sendiri sudah mempersonifikasikan sebuah pergeseran nilai dan posisi adiluhung marga Kǒng dan kemunculan masyarakat berbasis egalitarian. Seperti dijelaskan sebelumnya, Kǒng (孔) adalah marga paling dianggap mulia, yang dapat diartikan "pembuka", dan merujuk kepada pendiri ajaran konfusianisme. Kata Y̌̃ (乙) dalam bahasa Cina berarti kedua, sedangkan Jı̌ (己) berarti seseorang atau individu. Singkatnya, judul cerpen ini mengindikasikan pergeseran strata marga Kǒng dengan tradisi feodal dari kedudukannya yang tinggi di tengah masyarakat Cina menjadi posisi kedua.

Akan tetapi, penulis juga menggarisbawahi dalam cerpen "Kǒng Yîjǐ” pengarang tetap mengambil posisinya secara kritis dengan menggunakan sudut pandang orang pertama, yaitu seorang anak penjaga kedai.
Penggunaan sudut pandang ini dapat menunjukkan adanya jarak dari pengarang untuk menampilkan ide yang ia sisipkan, sebagaimana dijelaskan McKenzie (1972:16-17), penggunaan sudut pandang orang pertama tidaklah bersifat sepenuhnya reliable. Maksudnya, keberadaan sosok Kong dengan semua nilai yang dipegangnya bukanlah sosok yang ditolak mentah-mentah dan harus disingkirkan. Akan tetapi, nilai-nilai lama tetaplah bagian dari sejarah Cina dan setiap orang memiliki kebebasan untuk menganutnya atau tidak;

That was how Kong Yiji contributed to our enjoyment, but we got along all right without him too (Xun, 1980:56).

\section{Kesimpulan}

Berdasarkan penjelasan di atas, penulis menyimpulkan dalam mengkaji kesusasteraan Cina, aspek historis dan sosio-politik tidak dapat dipisahkan. Dalam kasus “Kǒng Yrijǔ” (孔 乙己) karya Lu Xun, refleksi penggambaran transisi dari pemerintahan dinasti ke republik terekam melalui medium sastra dan pergerakan budaya. Cerpen "Kǒng Y̌̌jị” menjadi kritik atas gagasan berbangsa yang masih mempertahankan nilai-nilai lama melalui representasi simbolis kejatuhan nilai-nilai konfusianisme dan tradisi feodal yang hidup di tengah masyarakat Cina. Oleh karena itu, cerpen ini mencoba menghidupkan kembali gagasan berbangsa yang diusung oleh para pembaharusalah satunya Lu Xun-yang lepas dari nilainilai lama, untuk membawa rakyat Cina ke masa depan yang lebih baik. Dengan dilakukannya 
kajian ini, penelitian lanjutan dengan model resepsi pembaca, baik itu yang berasal di negara Cina maupun belahan dunia lain, atas literatur Cina modern dapat mengemukakan persoalan yang lebih kontekstual, khususnya dalam konteks bangsa atau masyarakat yang mengalami pergulatan antara mempertahankan tradisi dan mengedepankan modernitas.

\section{Daftar Pustaka}

Brummett, Barry. 2009. Technique of Close Reading. London: Sage Publication.

Damono, Sapardi Djoko. 1978. Sosiologi Sastra: Sebuah Pengantar Ringkas. Jakarta: Departemen Pendidikan dan Kebudayaan.

Fokkema, Douwe W. 1977. "Lu Xun: The Impact of Russian Literature dalam Mere Goldman", Modern Chinese Literature in The May Fourth Era. London: Harvard University Press.
Foley, Todd. 2012. "Between Human and Animal: A Study of New Year's Sacrifice, "Kǒng Y̌̌jǐ", and Diary of a Madman". Front. Lit Stud. China Vol. 6 (3). DOI: 10.3868/s010-001-012-0022-5.

Hsia, C. T. 1961. A History of Modern Chinese Fiction 1917-1957. New Haven: Yale University Press.

Lu Xun. 1980. Lu Xun Selected Works Volume 1 (Diterjemahkan ke Bahasa Inggris oleh Yang Xianyi dan Gladys Yang). Beijing: Foreign Language Press.

McKenzie, Barbara. 1974. The Process of Fiction. Edisi kedua. San Diego: Harcourt Brace Jovanovich Publisher.

Tambling, Jeremy. 2007. Madmen and Other Survivors: Reading Lu Xun's Fiction. Hong Kong: Hong Kong University Press.

Wuryandari, Nurni Wahyu. 2006. "Kesusastraan Kontemporer Cina: Kontemporaritas dan Kebijakan Pe merintah". Jurnal Wacana Volume 8, No. 2 (hlm. 170-178).

Yangsheng Guo. 2006. "Modern Chinese Translation as Political Act". Jurnal NUCB JLCC, Volume 8, No. 3 (hlm. 15-24).

Yingjin Zhang, et al. 2016. A Companion to Modern Chinese Literature. United Kingdom: Wiley Blackwell. 